\title{
Ring chromosome 12 syndrome
}

INSERM

\section{Source}

INSERM. (1999). Orphanet: an online rare disease and orphan drug data base. Ring chromosome 12 syndrome. ORPHA:1439

Ring chromosome 12 syndrome is a rare chromosomal anomaly syndrome with a highly variable phenotype principally characterized by postnatal growth retardation, variable degrees of developmental delay and intellectual disability, microcephaly and facial dysmorphism (incl. epicanthal folds, low-set, cupped ears, prominent nose with flat nasal bridge, high arched palate, micrognathia). Skeletal abnormalities (e.g. pectus excavatum, clinodactyly), congenital heart malformations, cryptorchidism, café-au-lait spots and epilepsy have also been reported. 